professionals. Patients want to play an active role in their health care: it is about time we truly listened to them.

\section{Renata Drinkwater,}

Chief Executive, Self Management UK.

E-mail: renata.drinkwaterAselfmanagementuk.org

DOI: 10.3399/bjgp13X673856

\section{PITFALLS OF GPS GETTING BACK DIRECTLY INTO OUT-OF-HOURS CARE}

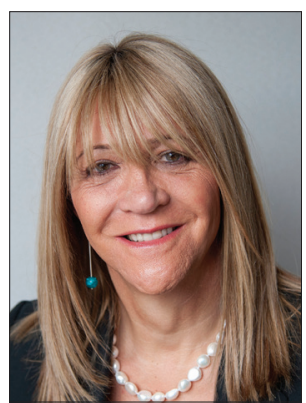

Michelle Drage

Recent ministerial pronouncements and media hyperbole around GPs being personally responsible and even personally providing out-of-hours care have sent shock waves throughout the profession. Such a reversal of an agreement that suited government as recently as 2004, is regarded by three generations of GPs as the last straw. For rural and city GPs alike, that agreement brought an end to constant battle against exhaustion, absence from family and home, marital breakup, neglect, and deterioration of personal health with no respite in sight. Demand for out-of-hours visits could not be stemmed, even by long, open-ended evening surgeries.

There was a terrible knock-on effect on daytime surgery; fatigue, decreased efficiency, irritability, increased risk of clinical error, and defensive practice. Despite our best efforts, patient dissatisfaction and complaints about in-hours and out-of-hours care rose inexorably and in an increasingly riskaverse, performance-driven environment the glue of collegiality and mutual support began to break down.

All of these are as relevant now as they were then, only more so. In-hours days are longer and far more complex than ever before, with consultation time being stretched to the absolute limit with the demands of QOF, the transfer of secondary to primary care, the multimorbidities that accompany longevity and medical advances, as well as ever-rising patient expectations and government targets.

While the GPs of the post-war baby boom era were prepared to both provide and be responsible for out-of-hours care, the GPs of the new baby boom are not. Now equal in numbers, male and female GPs are highly likely to have portfolio careers and less of a tie to life-long job security and satisfaction. They have grown up with different values in terms of work-life balance, shared parental roles, dual incomes, and other societal expectations.

Moreover, they are not trained to take back this archaic role of the clinicallyunnecessary 3 am visit for earache, based on politicians' rose-tinted memories of childhood. Nor are they prepared to take on responsibility for its organisation, in effect becoming the provider of last resort. How would they fit it into the 12-hour days they do already? How would patients receive continuity of care in hours? With doctors no longer living in the communities they serve, what about the journey times? What about the safety risk in our cities, towns, and rural highways? Who would look after the children at night when life partners are often living and working away from home to pursue their careers?

\section{"In-hours days are longer and far more complex}

than ever before, with consultation time being stretched ... with the demands of QOF, the transfer of secondary to primary care, the multimorbidities that accompany longevity ... as well as ever-rising patient expectations and government targets."
Life in New Zealand suddenly looks quite appealing, and if this notion is pursued we can expect many more GPs to pick up their families and go.

\section{Michelle Drage,}

Chief Executive, Londonwide LMCs.

E-mail: Michelle.Dragefalmc.org.uk

DOI: 10.3399/bjgp13X673865

\section{ARGUING FOR MORE GP ENGAGEMENT IN OUT-OF-HOURS CARE}

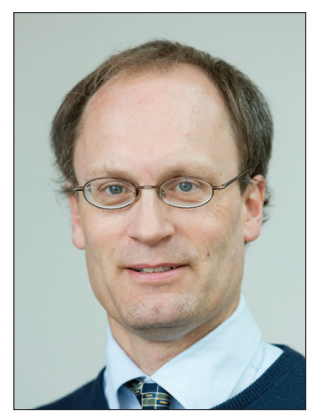

Denys Greenhow

There are three major disconnects causing problems with the quality of out-of-hours care provision loutside funding and staffing levels) that call on GPs to provide leadership. In the long term, GPs working exclusively in out-of-hours care shouldn't be revalidated as GPs unless they demonstrate keeping up to date with chronic disease management. Equally GPs mainly working in hours can be challenged by unscheduled care shifts. An out-of-hours session in is not equivalent to one in hours.

Disconnect two: no coherent clinical governance. Some private companies delivering out-of-hours care are designated bodies with their own responsible officers. However, most require their GPs to be on a performers list which will have its own responsible officer taking priority for their revalidation: why? Within many out-ofhours providers there are no regular peerto-peer meetings to discuss significant events. Confidentiality clauses also stymie transparency. The report by Colin-Thome $\&$ Fields on general practice out-of-hours services in England noted supervision of out-of-hours GPs was mainly through medical directors and indeed urged commissioners to separate discussions on service delivery from quality with providers to maintain focus. The National Out-ofHours Operations Group meets monthly to 


\section{"Within many out-of-hours providers there are no regular peer-to-peer meetings to discuss significant events.}

interconnect the service in Scotland, but in England only a small number of providers share significant events confidentially and compulsory national quality markers are benchmarked by non-government organisations such as the Primary Care Foundation.

Out-of-hours care is now provided by many professions who are discretely trained, such as unscheduled care nurses via a range of routes, paramedics with different guidelines and drugs in their kit, and BASICS trained doctors, anaesthetists, and emergency care clinicians all with stakes in unscheduled care. Coordination is needed.

What to be done? Creating a national quality spine/contract running through all providers of NHS patient care (both private and public) would answer these points. Such a contract signed by all providers and their employees would preclude any access to NHS patients. This would necessitate regular significant event meetings with a duty of candour with all interprofessional same-sector peers contracted and paid to attend, linked to appraisal, chaired by experienced outside monitors. National standards are also required for provision of equipment and drugs in out-of-hours care. The seeds are there following the Francis and Berwick reports and the College can lead the debate.

Conscription of practice-based GPs again into $24 / 7$ practice? ('Oh! we don't want to lose you, but we think you ought to go ..., as the WWI recruiting song had it). No, a better solution would be to buddy-up willing outof-hours GPs with practices to embed them locally to maintain their all-round practice and allow them to be link workers between the services, particularly with reference to vulnerable patients. And funding to achieve this public purpose.

\section{Denys Greenhow,}

RCGP North of Scotland Faculty Representative and Out-of-Hours Salaried GP, Easter Ross.

\section{E-mail: dengreenhowdyahoo.com}

\section{HOW PRIMARY AND SECONDARY CARE SHOULD WORK TOGETHER}

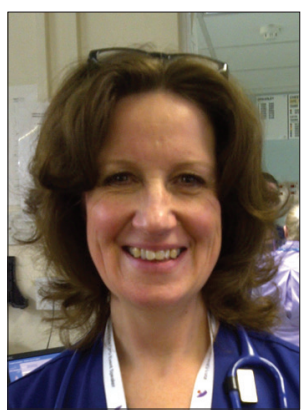

Suzanne Mason

Accident and emergency department (A\&E) visits and ambulance utilisation are rising in the UK despite a very strong network of GPs and universal coverage. The renegotiation of the GP contract has created a new gap in services in some parts of the country, where there are insufficient GPs to cover the emergency out-of-hours workload. Patients' perceptions of their clinical problem and their GPs' availability has changed such that their default position is increasingly to attend A\&E. The NHS began to address this issue some years ago by creating alternative services that patients could access for advice and management of their urgent healthcare problem such as NHS Direct, latterly replaced by NHS 111, and walk-in centres or urgent care centres. Studies have shown that paradoxically, these alternative services have led to an overall increase in demand for A\&E services, often because of confusion among the public about which service is available and when, and because of an increased expectation by the public of availability of 24/7 care. However, evidence to date suggests that collocation of services may have some impact on reducing $A \& E$ attendance.

It is clear from this evidence that out-ofhours services need to be joined up, easily accessible and focused on what patients actually want. There is simply no point in trying to redirect patients or prevent them from attending. The consumer mentality that exists in society today partly encouraged by the increased expectations that the NHS advertise, such as being seen and treated within 4 hours or calling '999' if we experience chest pain, have created a challenge for how we are going to meet these demands in a cost-effective and safe manner. Ultimately we have to accept that patients want an easily accessible one-stop shop where they can reliably access health care in an emergency. The simple solution is a collocated emergency centre staffed by GPs, nurse practitioners, and emergency medicine doctors offering a range of services for the public. However, key to the success of such ventures are funding streams that cross primary-secondary care boundaries, appropriate care pathways to refer patients into the centre and back out to the community and social care, GPs who want to undertake this work, and full support of local clinical commissioning groups. In addition, top-down initiatives, targets, and quality improvement strategies that actively disincentivise this joined-up approach must be removed. The time for working in silos and not taking a totally patient-focused approach to out-of hours care is over and to protect our future as clinicians, and the future care of our patients, we have a duty to convince government and the Department of Health that this is the future of out-of-hours health care.

\section{Suzanne Mason}

Professor of Emergency Medicine, University of Sheffield.

\section{E-mail: s.masondsheffield.ac.uk}

DOI: 10.3399/bjgp13X673883
"Accident and emergency department visits and ambulance utilisation are rising in the UK despite a very strong network of GPS and universal coverage. 